\title{
Ética Como Um Fator Integrante Da Responsabilidade Social Empresarial
}

\section{Ethics As An Integral Factor Of Corporate Social Responsibility}

\author{
Paulo Roberto Alves ${ }^{1}$, Tania Maia², Valério V. Bonelli ${ }^{3}$ \\ 1.Paulo Roberto Alves - Doutor em Ciências Sociais e Professor na FEA - PUC-SP. \\ 2.Tania Maia - Doutora em Ciências Sociais e Professora na FEA - PUC-SP. \\ 3.Valério V. Bonelli - Doutor em Ciências Sociais e Professor na FEA - PUC-SP.
}

\section{Resumo}

O resgate ético é de grande importância nas negociações empresariais como forma de responsabilidade e cumprimento dos acordos. Este trabalho procura resgatar o sentido da Ética, trazendo para o mundo empresarial, propondo a inclusão do fator "ética" como um dos pilares essenciais para a sustentabilidade tão presente na contemporaneidade, e várias são atualmente as discussões a respeito da sustentabilidade, estendendo-se aos mais diversificados meios empresariais, inclusive como apelo mercadológico, utilizandose dos slogans: "consumidores verdes", "ecologicamente correto", dentre outros, para atrair um número maior de consumidores através do discurso do "consumo consciente". Porém, até que ponto a lógica do consumo, ou seja, sua ideologia consumista permite que este seja "sustentável", "verde", "consciente"?

Palavras-chave: Desenvolvimento Sustentável; Sustentabilidade; Ética Empresarial.

\begin{abstract}
The ethical redemption is of great importance in the negotiations as a form of corporate responsibility and compliance with agreements. This paper seeles to uncover the meaning of ethics, bringing to the business world, proposing the inclusion of the factor "ethics" as one of the key pillars of sustainability so present in contemporary times, and several are currently discussions about sustainability, extending to more diverse business community, including as market appeal, using the slogans: "green consumers", "environmentally friendly", among others, to attract a larger number of consumers through the discourse of "conscious consumption". However, the extent to which the logic of consumption, ie, their consumerist ideology allows it to be "sustainable", "green", "conscious"?
\end{abstract}

Keywords: Sustainable Development, Sustainability, Business Ethics. 


\section{Introdução}

As décadas finais do século XX evidenciaram grandes transformações sociais, econômicas, políticas e culturais. A globalização da economia introduziu novos parâmetros no que diz respeito as relações do trabalho e nas relações entre Estado e sociedade trazendo as inovações tecnológicas, o desenvolvimento dos meios de comunicação, bem como a conquista no campo social e também trabalhista A concorrência sem fim, o individualismo e a busca incessante pelo lucro cada vez maior marcam as relações sociais e econômicas dos sistemas capitalistas desta época. $\mathrm{E}$ as conseqüências, tais como as desigualdades sociais, a degradação ambiental e o desemprego, marcam a sociedade contemporânea.

O resgate ético é de grande importância nas negociações empresariais como forma de responsabilidade e cumprimento dos acordos. Atualmente, diante da forte concorrência no mercado e da liberdade econômica proporcionada pela globalização, torna-se imperioso manter os negócios distantes da mentira, roubo, suborno e outras ações imorais envolvendo meio ambiente, relações trabalhistas e sociais sob a ótica moral e ética. O presente trabalho procura resgatar o termo Ética e trazêlo para o mundo atual do ponto de vista empresarial destacando as divergências existentes entre a retórica e a prática das instituições globalizadas, e diante do debate propor a inserção deste como fator integrante no conceito de sustentabilidade.

\section{Ética E Moral}

Para REALE (2000), a Ética é uma ciência normativa dos comportamentos humanos, não apenas comportamentos valiosos, mas obrigatórios, estando, então, presente o sentido imperativo da norma ética, a expressão do dever ser. $\mathrm{Na}$ distinção entre ética e moral destaca-se que o conceito de ética advém do que venha a ser a moral dos indivíduos, é o ato de decidir com consciência e honestidade como formato do comportamento humano. A moral faz parte integrante da cultura social, de maneira que impõe normas de conduta para a sociedade. Já a ética é o controle de qualidade dessa moral, o regimento que tem por objetivo a reflexão crítica do ato moral. NUNES (2004) traz uma diferenciação precisa do seu entendimento sobre a ética e a moral, conforme se verifica que a moral indica, assim, as grandes linhas gerais de comportamento do cidadão, reguladas pela sua consciência e pela tendência para a concretização dos objetivos individuais. A ética, por seu turno, indica as razões filosóficas das decisões de ação, ou seja, é a ciência que estuda as regras de comportamento e a sua fundamentação. Em linguagem corrente, ou em sentido usual, usamos o termo, ética, quando nos referimos à 
reflexão filosófica que tem como objeto a análise e a fundamentação do comportamento ou agir humano. A moral manifesta-se no comportamento humano, sob a influência da própria consciência, da cultura e costumes da sociedade. Já a intenção da ética é a imposição de regras, bem como a limitação desse comportamento do indivíduo na sociedade, por meio da punição, do cumprimento de norma legal ou mera conscientização, da mesma forma como age o direito.

No pensamento de IHERING, in FERRAZ (2007), do mesmo modo, a Ética está relacionada à conduta moral do indivíduo, ou seja, se o indivíduo é o sujeito final da moral, então a inobservância das normas morais deve manifestar-se na dimensão do bem-estar, assim, a sua observância evidencia-se em sua elevação. O entendimento do autor é de que todo e qualquer indivíduo que reconhece sua conduta imoral dentro de uma sociedade, acaba por elevar sua conduta ética, ao passo que a capacidade de reconhecer o que venha a ser antiético, torna o indivíduo nobre, de conduta elevada e consciente de suas ações, dos seus direitos, deveres e realizações no contexto social onde está inserido.

VÁZQUEZ (2003) entende que a moral se refere ao comportamento adquirido ou modo de ser conquistado pelo ser humano, todavia a ética significa "caráter" enquanto forma de vida também adquirida e conquistada pelo ser humano. Desse modo, expõe seu conceito sobre a moral: A moral é um sistema de normas, princípios e valores, segundo as quais são regulamentadas as relações mútuas entre indivíduos ou entre estes e a comunidade, de tal maneira que estas normas, dotadas de caráter histórico e social, sejam acatadas livre e conscientemente, por uma convicção íntima, e não de umas maneiras mecânicas, externas ou impessoais. Enfatiza-se no caso que o ato moral é voluntário, mas acaba por fazer parte de um contexto normativo (código moral) que vigora em determinada sociedade e acaba por dar the sentido. Sendo contexto normativo, argumenta que existe evolução moral todas as vezes que processe mudanças históricas que fazem os indivíduos pensarem e agirem com mais responsabilidade e com mais liberdade.

Os preceitos morais evoluem conforme evolui a sociedade; o que é correto atualmente pode não ser mais usual amanhã, e o indivíduo deve ser livre para acompanhar as mudanças. Uma vez adaptado às normas atuais, acaba por elevar sua conduta ética, e valorizar as ações que não tinham valor anteriormente, da mesma forma acontece com as empresas que atualmente adotaram uma nova concepção na forma de administrar os negócios, acompanhando as mudanças e anseios da sociedade.

\section{Ética No Meio Empresarial}

A ética empresarial centra-se na concepção de Empresa enquanto organização Econômica e instituição social, ou seja, um tipo de organização que desenvolve uma atividade 
que lhe é peculiar e da qual resulta a função que deverá exercer perante a Sociedade, e a direção que deve seguir para tomada de decisões.

A importância da ética no contexto empresarial manifesta-se de forma ampla no ordenamento jurídico brasileiro, tendo respaldo na Constituição Federal no capítulo da Ordem Econômica e Financeira, estampados no capítulo I, do título VII, com os princípios éticos que norteiam a atividade empresarial, como a valorização do trabalho humano e da livre iniciativa à repressão ao abuso do poder econômico, o incentivo à livre concorrência e a atuação do Estado na iniciativa privada, e ainda, no $\int 4^{\circ}$, do art. 173 , estão estabelecidas as práticas irregulares que devem ser evitadas na exploração da Atividade econômica, exatamente por ferir a ética empresarial.

A legislação constitucional prevê a possibilidade do acompanhamento mais rigoroso das práticas empresariais no tocante à ética nos negócios, permitindo que os órgãos de fiscalização e a própria sociedade adotem medidas judiciais necessárias para coibir os abusos cometidos pelas empresas. Embora a legislação constitucional traga essa previsão, alguns abusos cometidos no interior das empresas não possuem o amparo legal, necessário se faz, então, estruturar uma grande empresa em preceitos éticos e morais como base de sustentação das ações responsáveis, uma vez que os comportamentos não éticos no interior de uma organização merecem um controle interno, que possam gerar custos elevados para as empresas e conseqüentemente prejuízo à sociedade. A importância do reconhecimento da ética no ambiente interno e externo das Empresas atualmente é um fator importante, muitos administradores devem reexaminar, inclusive o comportamento ético dos indivíduos que compõem a empresa por entenderem que a ética está relacionada à ação prática individual dos homens, podendo refletir tais ações na sociedade.

As relações éticas facilitam e solidificam os laços de parceria empresarial de forma interna com empregados ou com os sócios, e de forma externa com os consumidores, clientes e toda a sociedade, de modo que as ações éticas acabam ocorrendo em função do respeito que um agente ético gera em seus parceiros. Incluem-se nas ações éticas empresariais o fator responsabilidade como sendo o termo mais importante deste contexto, pois não basta $\mathrm{o}$ cumprimento dos deveres, é necessário o cumprimento dos deveres com responsabilidade, isto é, a empresa que age com princípios éticos faz a previsão da conseqüência dos seus atos muito antes de colocá-los em prática, de forma a prevenir os riscos e não trazer prejuízos para si ou para a sociedade.

WEBER (2005) traz estas considerações, explicadas por meio de duas teorias, a Ética da convicção, entendida como deontologia (estudo dos deveres) e a Ética da Responsabilidade, conhecida como teleologia 
(estudo dos fins humanos), expondo algumas considerações: [...] toda a atividade orientada segundo a ética pode ser subordinada a duas máximas inteiramente diversas e irredutivelmente opostas. Pode orientar-se segundo a ética da responsabilidade ou segundo a ética da convicção. Isso não quer dizer que a ética da convicção equivalha à ausência de responsabilidade, e a ética da responsabilidade a ausência de convicção. Não se trata disso, evidentemente. Não obstante, há oposição profunda entre a atitude de quem se conforma às máximas da ética da convicção - diríamos, em linguagem religiosa, "O cristão cumpre com seu dever e, quanto aos resultados da ação, confia em Deus" - e a atitude de quem se orienta pela ética da responsabilidade, que diz: "Devemos responder pelas previsíveis consequências de nossos atos" (2005).

Verifica-se, no pensamento de WEBER (2005) a existência de um confronto de ideias entre tradição e modernidade. Enquanto a ética da convicção tem seus fundamentos nas tradições passadas e internalizadas pelo indivíduo, não se preocupa com o resultado das ações. Já a ética da responsabilidade faz com que o indivíduo repense suas decisões, não deixando aos outros a responsabilidade futura de seus atos.

A teoria da responsabilidade de WEBER conceitua e respalda a concepção da Ética empresarial de modo a efetivar as decisões negocia com maturidade e consciência, e assumir suas responsabilidades perante a sociedade. A
Ética apoiada na convicção não é adequada para os tomadores de decisão das grandes empresas, que precisam se reposicionar diante dos seus atos, uma vez que estes terão implicações externas e abrangerão toda coletividade.

Nesse sentido, importante ressaltar a significação da ética ambiental no ambiente empresarial, sendo esta a conduta de comportamento do ser humano na natureza cuja base primordial está na própria conscientização ambiental e no compromisso da preservação da natureza.

Deve-se ter em conta que optar pela ética ambiental no ambiente empresarial é caminhar pela mão contrária aos interesses econômicos, fator preponderante dentro de uma sociedade neo-capitalista, levando-se em consideração a fácil tendência de utilização de matéria prima da natureza de forma indiscriminada. Daí a necessidade da conscientização e mudança de paradigmas ético empresariais, de modo que deverão cumprir não apenas as obrigações legais, mas morais e éticas, posicionando o empreendedor frente à natureza, refletindo em ações que darão resultados positivos.

Considerando o meio ambiente como um direito fundamental, e Direito Difuso preconizado pela Constituição Federal, é importante lembrar que ele é também um dever fundamental, ou seja, ao mesmo tempo que proporciona liberdade, exige-se a responsabilidade. 


\section{Ética E Direito}

Diante desse posicionamento, cabe agora fazer a relação entre a ética e o direito, e atentar para a significativa comparação nas relações empresariais e sociedade, reforçando o conceito de que a ética é uma conduta oriunda do comportamento humano, é a teoria do comportamento moral do homem em sociedade, enquanto o direito é uma conduta oriunda de preceitos legais impostos à sociedade.

Uma diferença significativa entre as normas morais e o direito está na interioridade da moral e na exterioridade do direito. O indivíduo interioriza as normas morais e conscientiza-se de que as deve cumprir. Ao passo que no direito, o indivíduo não interioriza a norma legal, apenas a cumpre de forma exteriorizada ainda que não esteja convencido de que é justa. Isso demonstra que o cumprimento das normas morais não é garantido por regra coercitiva advinda da vontade, o cumprimento é exigido pela simples consciência do indivíduo. $\mathrm{O}$ direito, ao contrário, exige tal dispositivo legal, e impõe a observância da regra jurídica e a obrigação de comportar-se independentemente da vontade.

Portanto, pode-se afirmar que, quando um indivíduo ou um grupo de indivíduos regulam as suas relações, não sob a ameaça de uma pena ou coação, mas pela íntima convicção da sua consciência de que está agindo corretamente, essas ações demonstram um elevado comportamento moral e o crescimento e maturidade desses indivíduos no âmbito social. Diz-se no âmbito social porque as ações moralmente corretas advêm de uma determinada sociedade, não é o indivíduo que altera as regras do fazer ou não fazer. A própria sociedade onde está inserido é que impõe as regras morais que devem ser seguidas. Nesse passo, “o indivíduo decide e age no âmbito de uma obrigatoriedade socialmente dada".

Esse alcance da norma ética nas sociedades, como conduta moral respeitada, manifesta-se com força e poder de conquistar espaços inimagináveis, quando revestida de uma maior valoração do que as normas jurídicas. Nesse entendimento, Nunes explica que, embora a norma ética não implique sanção pelo descumprimento, ainda assim representa maior efetividade no seu cumprimento. A diferença entre ética e o direito resulta do fato de que o cumprimento da norma jurídica é imposto por coação, podendo ser considerado como uma forma de sanção, entre outras possíveis, para o indivíduo. Enquanto face ao não cumprimento de uma norma moral temos o surgimento de um sentimento de culpa perante a sua própria consciência. Então, apesar de não haver sanções legais para o não cumprimento das regras morais, a força que elas contêm faz com que sejam obedecidas para além da norma jurídica. $\mathrm{O}$ 
fato de o direito ser imposto por coação como forma de sanção não representa tanta força como o descumprimento dos preceitos éticos, por serem oriundos da própria consciência humana, que dita as regras de conduta moral para viver em sociedade.

Considerando o Direito e a Ética como normas de conduta, é evidente que em uma sociedade possam existir leis que agradam e amparam alguns indivíduos e desagradam a outros, criando uma situação de conflito. Nesse caso, é necessário que existam as regras morais básicas cumpridas pelos indivíduos para que se chegue ao equilíbrio e à sua satisfação. Da mesma forma deve agir a empresa, atendendo aos preceitos legais e incorporando uma conduta ética, moralmente aceita perante a sociedade.

Para Cardoso (2008), o entendimento é que não há necessidade de se padronizarem regras morais básicas de conduta para se alcançar a eticidade de uma organização empresarial, quando a própria sociedade se incumbe de fiscalizar e julgar o seu comportamento. Nesse sentido, só a pressão social pode contribuir para que o mundo dos negócios se torne mais virtuoso. As crescentes expectativas da opinião pública na moralização dos negócios acabam por conduzir ou deveriam conduzir a um reforço moral dos gestores. Os comportamentos não éticos das empresas como o alto índice de corrupção, práticas imorais ou o descumprimento das obrigações fiscais, fraude nos produtos, geram no mercado consumidor uma situação negativa. A Empresa deve agir com a ética da legalidade ao pagar seus impostos e seguir as determinações legais, considerado o "mínimo ético" possível em uma organização empresarial.

Em 2001, fraudes contábeis foram descobertas na Empresa americana do setor energético "Enron", quando executivos maquiavam balanços da empresa para desviar centenas de milhões de dólares. Mais recentemente, empresários da alemã Volkswagen pediram demissão depois da descoberta de um dos maiores escândalos corporativos da Europa, também envolvendo desvios de dinheiro. A integridade e honestidade são fatores de grande importância para a imagem organizacional. O envolvimento com fraudes e atos de corrupção abala consideravelmente a postura sólida à sociedade.

Nunes (2004), ao tratar do tema corrupção e suborno, classifica um comportamento como corrupto, quando uma pessoa que ocupa determinado cargo numa empresa, procura por meio desta situação privilegiada, obter um benefício ilegítimo para si próprio, para determinado grupo, ou para a própria empresa. Quanto ao suborno, entende a autora que se trata de um aliciamento de influências para exercer indevidamente suas funções e ignorar regulamentos de segurança, atenuar condições fiscais e dar um tratamento preferencial em troca de algum tipo de compensação.

\section{Os Códigos De Ética}


Para lidar com essas situações e não cair em descrédito perante o mercado, as empresas buscam alternativas que, se não resolverem por completo, pelo menos amenizam a condução das práticas empresariais. Essas alternativas são as espécies de controle interno das empresas, nomeadamente os Códigos de Ética e a Auditoria Social. Várias empresas atualmente já vêm adotando os códigos de conduta que servem de orientação de comportamentos. Esses códigos, mais conhecidos como "Códigos de Ética" são declarações de princípios que permitem mecanismos de controle para ajudar a regulação interna das empresas, devem conter regras explícitas para as tomadas de decisões nos casos concretos. Um destes exemplos pode ser observado por Santos (2011), profissional responsável pelo Departamento ao Cliente (DAC) e Marketing Jurídico de um escritório de advocacia. Para enfrentar uma concorrência cada vez mais acirrada, o escritório tem adotado uma conduta ética em seu marketing de relacionamento, que tem se apresentado como um instrumento de diferenciação entre os escritórios de advocacia. A autora menciona que neste universo jurídico, um dos fatores determinantes para a contratação dos serviços é a confiança, e o marketing de relacionamento entra neste cenário com o objetivo de assegurar esta confiança a todo momento. Este tipo de relação vai permitir não só que o cliente confie e mantenha uma relação estreita com o escritório, mas indique os serviços jurídicos a outras pessoas, muito comum neste tipo de setor. $\mathrm{E}$ a fórmula de manter este nível de relacionamento é por meio da ética e transparência, com funcionários treinados para que possam dar um atendimento correto ao cliente. Se o público interno não estiver em sintonia com os valores e cultura da empresa, dificilmente o escritório sobreviverá já que depende desta relação de confiança entre funcionário e cliente. Para a autora, "O atendimento deve ser feito de maneira rápida e eficaz, satisfazer todos os desejos e necessidades, e mais do que isto, encantar o cliente". Encantar, neste contexto, significa superar expectativas oferecendo um atendimento de excelência. E para oferecer este tipo de atendimento o funcionário precisa estar satisfeito, motivado e ser treinado.

A autora lembra que em muitos escritórios os clientes se deparam com secretárias automatizadas, que repetem frases de efeito como a de um serviço de telemarketing. A chance do cliente ficar insatisfeito e ofendido é enorme. Fica clara a estreita relação do endomarketing com o marketing de relacionamento, bem como sua importância dentro do contexto, uma vez que todos os funcionários precisam estar conscientizados de que somente através de um atendimento exemplar, é possível conquistar e fidelizar o cliente, deixá-los satisfeitos e com seus direitos atendidos.

$$
\text { Como se pode observar com o caso }
$$
ilustrativo acima, a conduta ética ou moral é 
relativa a cada ambiente cultural. Depende da cultura e dos costumes de cada local. Não há meio de generalizar regras e condutas se o entendimento de uma sociedade é diverso da outra. O que é ilícito numa sociedade pode não ser para outra. Contudo, as condutas éticas praticadas numa sociedade, por meio de hábitos e costumes, podem representar um regramento mais efetivo do que o próprio regramento jurídico.

As empresas que buscam a implementação das práticas sociais devem ter uma postura de autêntica responsabilidade no que tange ao seguimento das regras de conduta, pois deverão ser adaptadas às regras morais e éticas da sociedade onde estão inseridas, uma vez que os Códigos de Ética ou de Conduta são as normas legais de cumprimento efetivo que regulamentam tais ações. Os referidos Códigos poderão abranger inclusive o Sistema Contábil e Financeiro da Empresa, estruturados de forma a permitir a pesquisa e identificação de operações irregulares, bem como poderá incluir orientações sobre a Ouvidoria, onde serão elaboradas análises imparciais sobre determinado problema e encaminhado ao departamento competente para resolução da pendência, de forma eficaz e precisa.

Os Códigos de Ética poderão detalhar para cada relacionamento da empresa quais os princípios que deverão ser seguidos na prática diária e que tornarão referência para as ações empresariais. Estas normas estabelecidas para o trabalho se traduzem em um Regimento ou
Código de Regulação, e a possibilidade de ser aceito no ambiente empresarial ficará atrelada à sustentação dos princípios éticos.

Segundo Fernandez (2004), os princípios éticos estruturais de um Código de Ética empresarial são: “a legalidade, o profissionalismo, a confidencialidade, a fidelidade, as responsabilidades concretas, a boafé, a ausência de conflito de interesses e o respeito integral pelas pessoas”.

O Princípio da Legalidade é fundamental para manter a ordem, uma vez que regula o comportamento dos indivíduos. Constitui o mínimo que a pauta de convivência social deve observar para que haja uma convivência pacífica, segura e harmoniosa, de maneira que se consubstancie como um dos princípios gerais do Direito. O Princípio do Profissionalismo está ligado ao desempenho dos empregados da empresa e dos gestores, buscando, em primeiro lugar, o aprimoramento de conhecimentos para maior rendimento das funções e maior eficiência. A cooperação é fundamental, inclusive, com atuação em outros setores diferentes.

Ser profissional é estar sempre preparado para receber e dar informações para as pessoas, com a responsabilidade suficiente para que essas informações sejam verdadeiras, precisas, necessárias, completas e oportunas. $\mathrm{O}$ bom profissional também deve conhecer e cumprir as normas legais e éticas e estar atento para a prevenção de riscos. Desse modo, estará contribuindo para o bem-estar de todos à sua 
volta. O Princípio da Fidelidade está intimamente relacionado com os Princípios da Contábeis por exemplo, onde; buscam a clareza e veracidade de todos os atos econômicos da empresa, sobre todas as mutações sobre o patrimônio, de forma a captar as informações pela contabilidade patrimonial, financeira, e econômica, considerando-as nos balanços sociais e demonstrar os resultados. Do mesmo modo está o Princípio da Confidencialidade com respeito ao sigilo Profissional que tem o objetivo de preservar a intimidade sobre questões pessoais ou profissionais. A preservação do sigilo de dados sobre certas transações comerciais é um fator importantíssimo para as empresas, quando do jogo da competição e concorrência pelos mercados afora.

O Princípio da Boa-fé diz respeito à intenção dos indivíduos nas ações empresariais de forma verdadeira para que as ações sejam confirmadas e convalidadas. A boa-fé objetiva é concebida como regra de conduta fundada na honestidade, lealdade e no princípio da consideração e do respeito. Este último, o Princípio do respeito, age livremente em função de um plano próprio e tem algumas características que o compõem como a privacidade, veracidade e autonomia. Cabe evidenciar que esse regulamento é estritamente interno, embora dependendo das ações praticadas, que podem ser aplicadas às normas jurídicas convencionais, conforme já exemplificado anteriormente. Apesar de o Código de Ética, ser peculiar a uma empresa específica, com características pessoais e internas, estas devem ser aceitas, em nível nacional, para que possam ter credibilidade e servir de modelo para outras empresas.

Em alguns Códigos de Ética, tanto de empresas nacionais quanto de estrangeiras verifica-se primordialmente um regramento de condutas fortalecido pela inclusão dos princípios citados, uma fonte de orientação fundamental para a condução dos negócios empresariais. Contudo, os Códigos de Ética permitem promover o relacionamento da empresa com a sociedade, refletindo a sua conduta social de acordo com as regras básicas de cidadania, com uma gestão eficiente, com respeito aos stakeholders, com qualidade dos produtos e com respeito aos direitos fundamentais dos indivíduos.

Cabe pontuar que a adoção por um código de ética empresarial não significa simplesmente escrever uma série de tópicos como se fossem ordens ou mandamentos aos empregados. As suas palavras terão de refletir os valores realmente praticados para que sejam interiorizados em todos os níveis da organização e exteriorizado.

Para moldar e efetivar os comportamentos e atitudes é necessário que a empresa promova o diálogo sobre as questões éticas, além de acompanhar, avaliar, cobrar, recompensar e estimular, é necessário entender que a organização é apenas um subsistema dentro da sociedade, e que a cultura 
organizacional também é parte da própria cultura da sociedade que a cerca. Mais do que isso a organização precisa agir eticamente com os atores externos principalmente, clientes, consumidores, fornecedores, entre outros.

A responsabilidade empresarial de acordo com FERRAZ, efetiva e legítima consolida-se justamente na fusão da ética com o direito, tanto do cumprimento dos preceitos legais e da condução empresarial embasada nos preceitos éticos e morais, como uma carta de valores e princípios dispostos ao resgate da cidadania.

\section{Considerações Finais}

O atual tripé no qual deveria assentar-se o "Desenvolvimento Sustentável": fatores econômicos; fatores sociais; fatores ambientais, desde então, percebe-se que o capital caso não houver pressões legais e sociais, tende a privilegiar mais o fator econômico.

Da mesma forma, a responsabilidade empresarial deverá alcançar os anseios de toda uma sociedade na tomada de decisões, implementando princípios que possam estabelecer normas de boa convivência, maior produtividade, eficácia nos serviços, qualidade no atendimento e preocupação com os direitos do indivíduo, tanto internamente como externamente.
Nos dias atuais, os termos: "Desenvolvimento Sustentável" e "Sustentabilidade" são utilizado nos mais variados espaços, inclusive o empresarial, que nada mais vem observando nesta questão do que um amplo nicho mercadológico. Assim, todos os dias, uma variedade de produtos é introduzida no mercado, com propagandas do tipo: "Eco", "Verde", "Sustentável", ao mesmo tempo em que se difundem os valores consumistas da sociedade capitalista, empresarial e midiático o que acende, no imaginário coletivo, a falsa idéia de que o consumo "ecologicamente correto" é suficiente para que a degradação ambiental seja superada. Observa-se com o passar dos anos o crescimento da tecnologia industrial, do lucro, da privatização da natureza e a continuidade de uma desigual distribuição de renda. A sustentabilidade vai além da necessidade de dar bases ecológicas aos processos produtivos, de inovar tecnologias para reciclar os rejeitos contaminantes, de incorporar normas ecológicas aos agentes econômicos, ou de valorizar o patrimônio de recursos naturais e culturais para passar a um desenvolvimento sustentável pleno. A busca pela sustentabilidade não só responde à necessidade de preservar a diversidade biológica para manter o equilíbrio ecológico do planeta, mas também de valorizar a diversidade étnica e cultural da espécie humana e fomentar diferentes formas de manejo produtivo da biodiversidade em harmonia com a natureza, tendo como base fundamental o fator Ético.

Uma instituição responsável poderá alcançar a sua viabilidade econômico-financeira, 
evitando as práticas fraudulentas e antiéticas com a introdução dos regulamentos internos, como meio de conduzir as negociações empresariais com respeito e liberdade econômica.

\section{Referências}

CARDOSO, Luís Antônio. O Conceito de racionalização no pensamento social de Max Weber: entre a ambigüidade e a dualidade. Teoria e Sociedade $n^{\circ} 16.1$ - janeiro-junho de 2008

CAPPELLI, C. \& LEITE, J.C.S.P. Transparência de processos organizacionais. II simpósio Internacional de Transparência nos Negócios. Disponível em: http://www.latec.uff.br/transparência/ documentos/anais_transparencia2/T6_0115_0 129.pdf. Acesso em 20 de ago 2014.

CARDOSO, Carlos Cabral. Ética e Responsabilidade Social, in GOMES, Jorge F. S.,

REGO, Armênio. (coord.) Comportamento Organizacional e Gestão. Lisboa, Ed. RH, 2006,

CHERQUES, Hermano Roberto Thierry. Max

Weber: o processo de racionalização e o desencantamento do trabalho nas organizações contemporâneas. Revista de Administração Pública. RAP. Rio de Janeiro 43(4): 897-918, jul./ago. 2009

FERNANDEZ, J.L.F., Ética para empresarios y directivos, Esic Editorial, Madrid, 1994,

FERRAZ, A. C. S. L., A responsabilidade social como estratégia empresarial de desenvolvimento. Dissertação apresentada ao Programa de Mestrado em Direito da Universidade de Marília, como exigência parcial para obtenção do grau de Mestre em Direito; Marília, 2007

NUNES, Cristina Brandão. A ética empresarial e os fundos socialmente responsáveis. Ed. Vida Econômica: Portugal, 2004, p.22.

REALE, Miguel. Lições Preliminares de Direito. 25. ed., São Paulo: Saraiva, 2000

SANTOS, H.D. O marketing de relacionamento para escritórios de advocacia. Disponível em http://www.boletimjuridico. com.br/doutrina $/$ texto.asp?id=2037. Acesso em 30 abr. 2011.

200 ALVES, P.R.; MAIA, T.; BONELLI, V.V.: Ética Como Um Fator Integrante Da Responsabilidade Social Empresarial 
SOUSA, Luiz Gonzaga de. Ética e

Sociedade.Disponivel www.eumed.com.net, Acesso em 13.08.2014.

VÁSQUEZ, Sánchez A. Ética. ed. Trad. João Dell'Anna. Rio de Janeiro: Civilização Brasileira, 2003.

WEBER, Max. Ciência e Política. Duas

Vocações. São Paulo: Martin Claret, 2002

WEBER, Max. Economia e Sociedade: fundamentos da sociologia compreensiva. Tradução de Regis Barbosa e Karen Elsabe Barbosa; Revisão técnica de Gabriel CohnBrasília, DR: Editora Universidade de Brasília: São Paulo: Imprensa Oficial do Estado de São Paulo, 1999.

WEBER. Max. A ética protestante e o espírito do capitalismo. Tradução de M. Irene Szmrecsányi e Tamás Szmrecsányi. São Paulo: Pioneira Thomson Learning, 2005. 